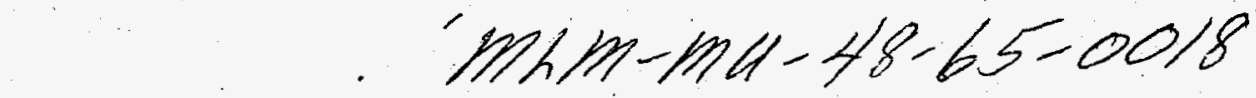

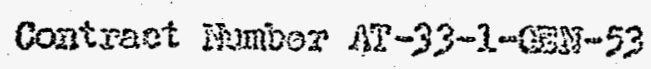

$-1$.

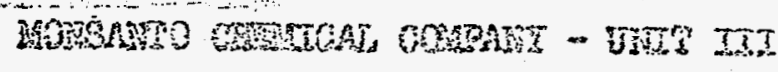

DUTW, OHO

$$
\begin{array}{r}
\text { RECEIVED } \\
\text { OCT } 11995 \\
\text { OSTI }
\end{array}
$$

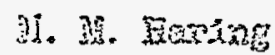

INt)
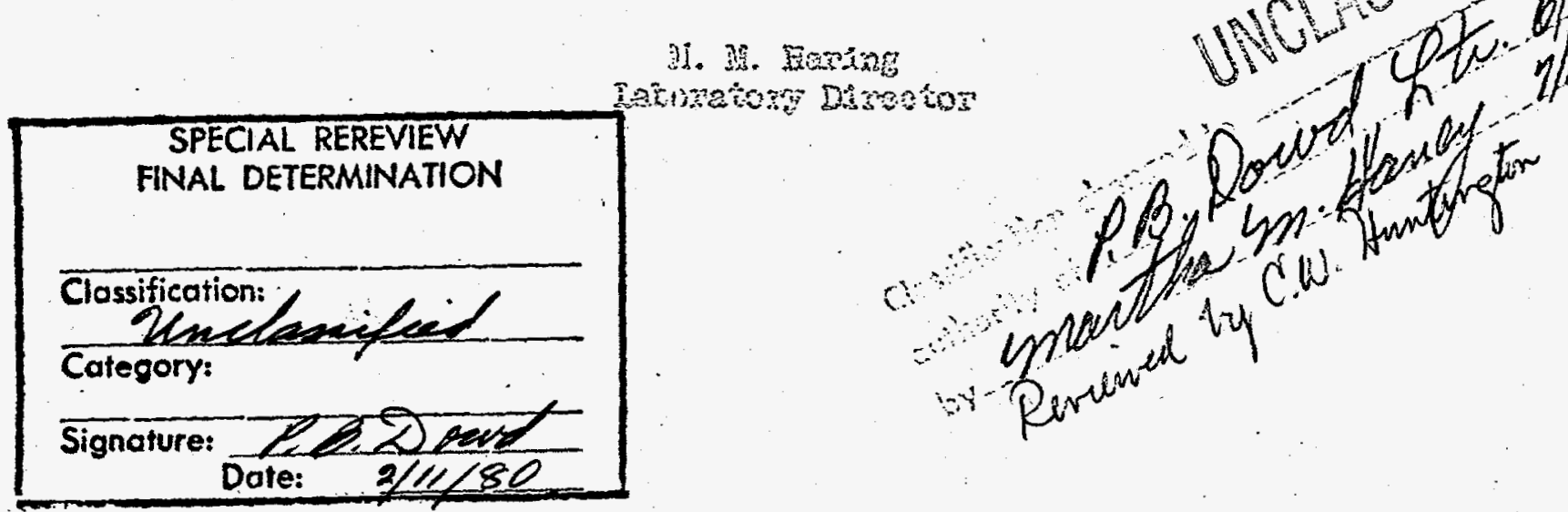

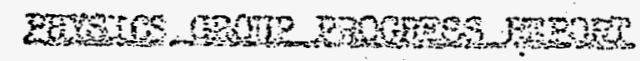

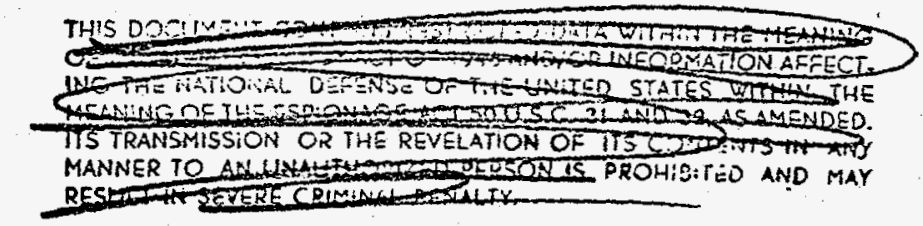

DISTRIBUTION OF THIS DOCUNENT IS UNLIMITED

UNCLASSIEIED.

DT

Dete: 3isy 1-31, 1948

Propared by: E. 2. Kanss

Dietrabutoa: sa

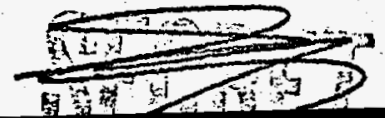




\section{DISCLAIMER}

This report was prepared as an account of work sponsored by an agency of the United States Government. Neither the United States Government nor any agency thereof, nor any of their employees, makes any warranty, express or implied, or assumes any legal liability or responsibility for the accuracy, completeness, or usefulness of any information, apparatus, product, or process disclosed, or represents that its use would not infringe privately owned rights. Reference herein to any specific commercial product, process, or service by trade name, trademark, manufacturer, or otherwise does not necessarily constitute or imply its endorsement, recommendation, or favoring by the United States Government or any agency thereof. The views and opinions of authors expressed herein do not necessarily state or reflect those of the United States Government or any agency thereof. 


\section{DISCLAIMER}

Portions of this document may be illegible in electronic image products. Images are produced from the best available original document. 


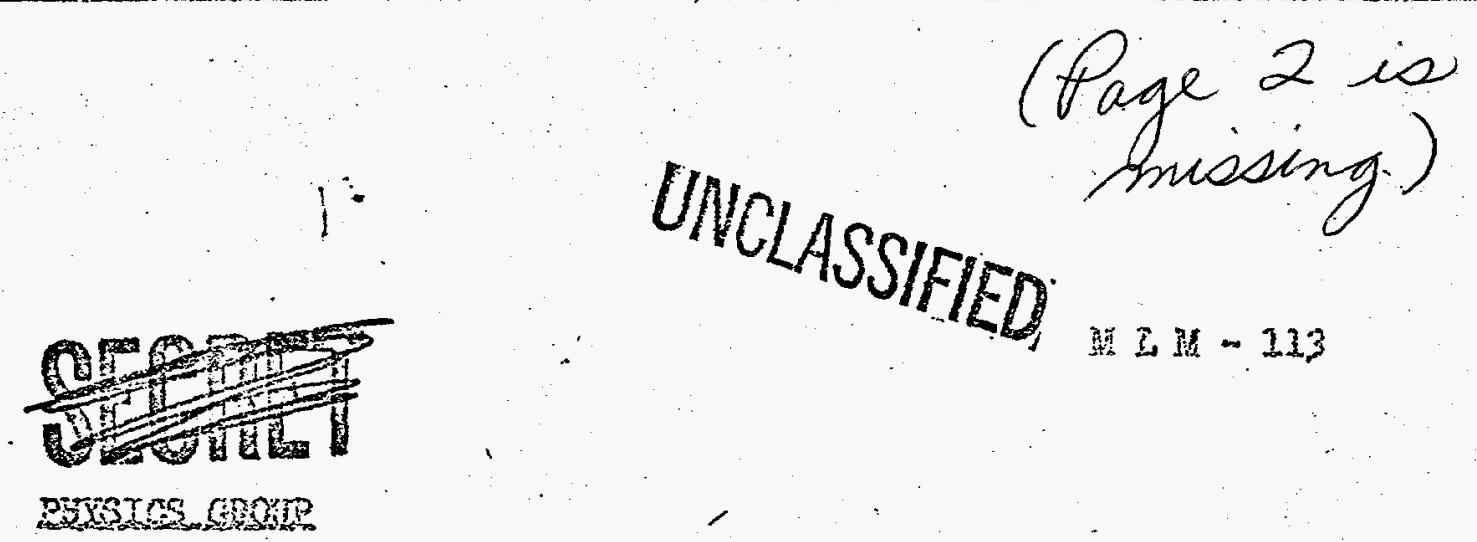

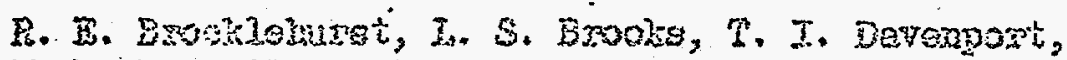

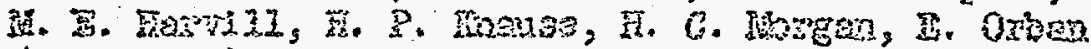

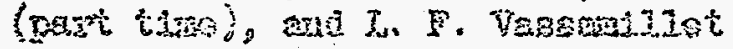

\section{GSPBOT}

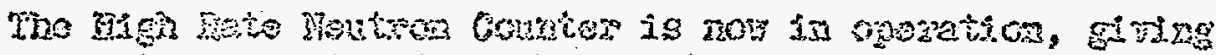

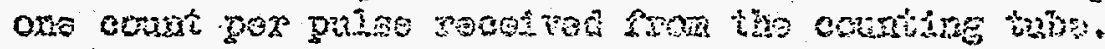

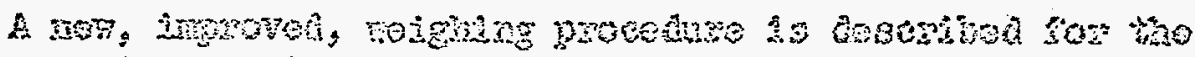
Tacuu Es?

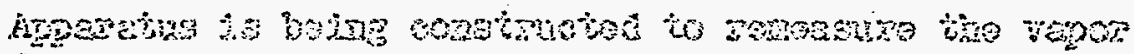

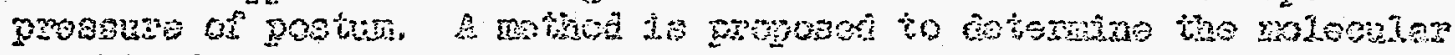
Feiditi of postu varos.

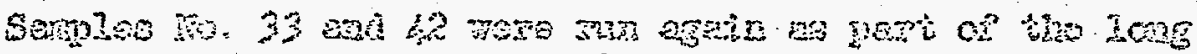

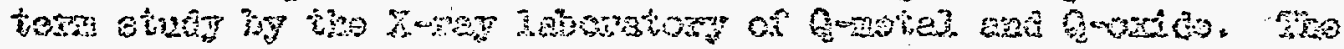

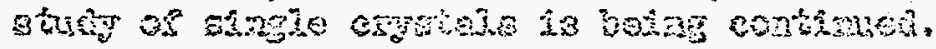

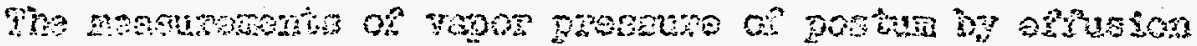

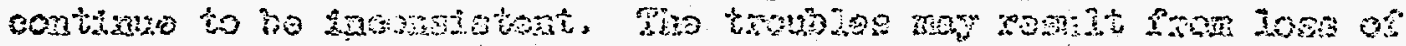
axtivitu by loge.

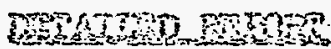

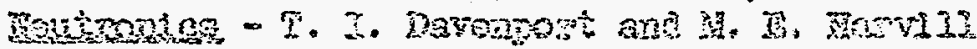

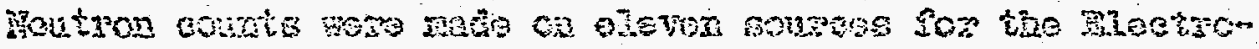

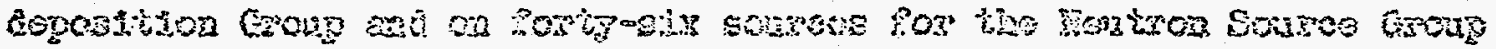
durias the pordod of the sopors.

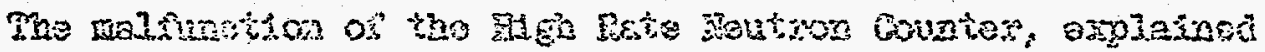

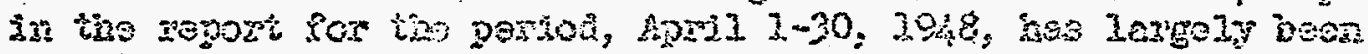

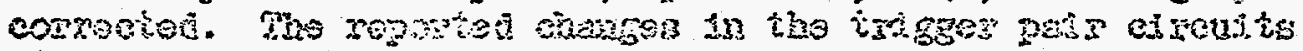

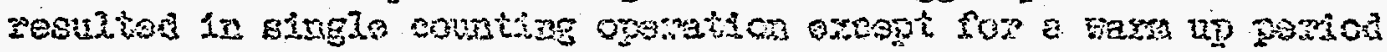

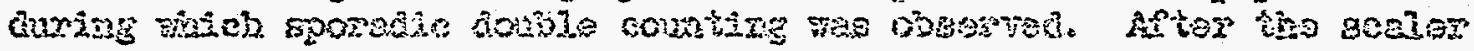

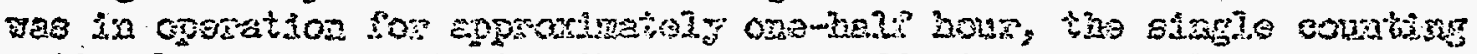

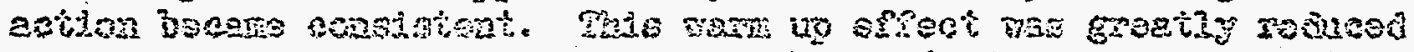

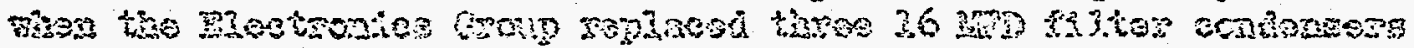

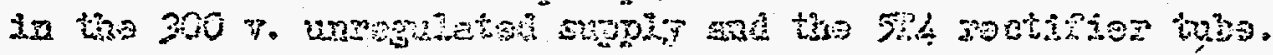

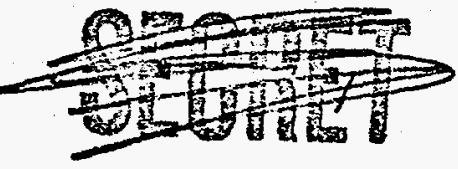




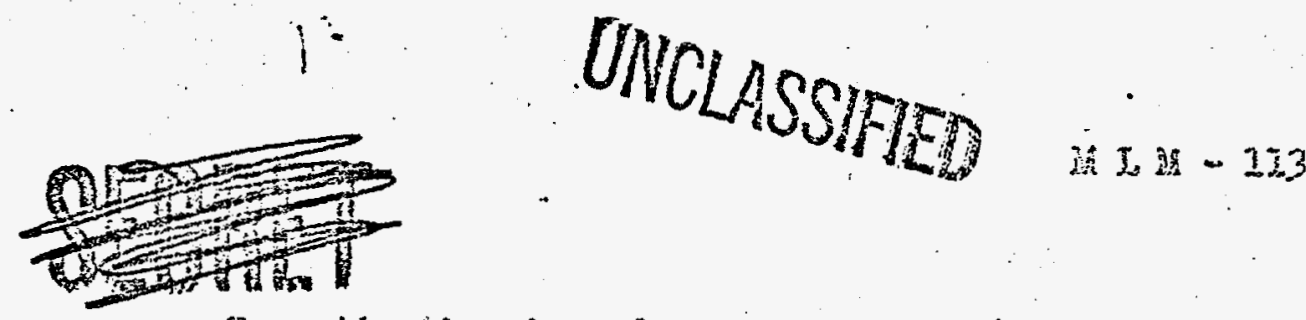

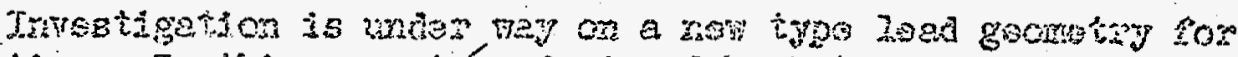

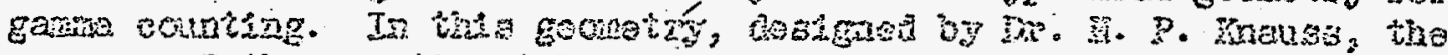

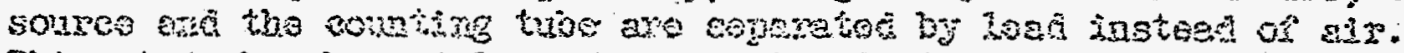

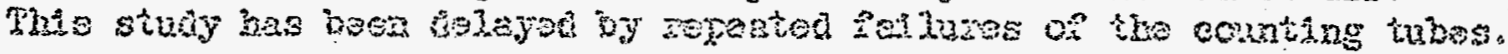

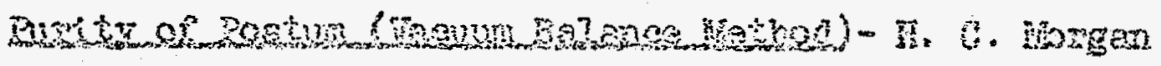

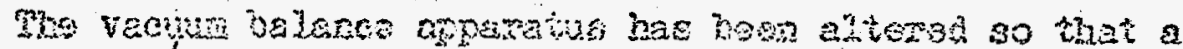

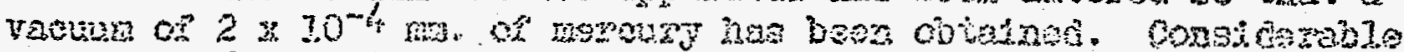

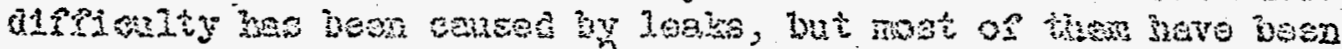

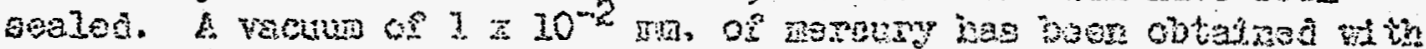

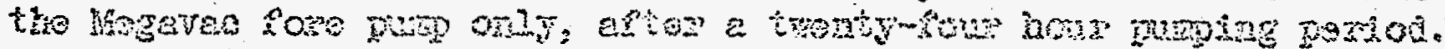

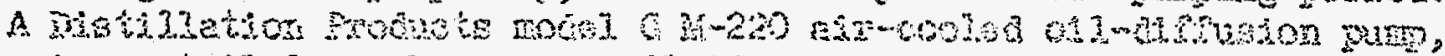

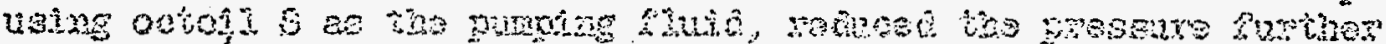

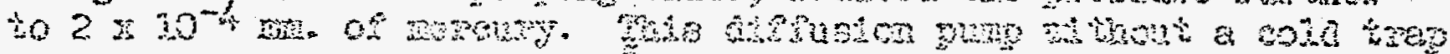
0. baspig

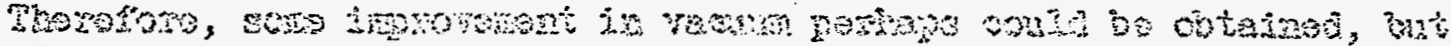

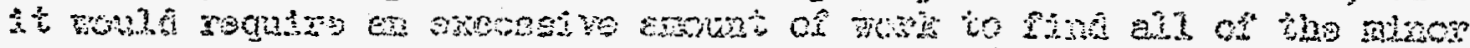
lotisis.

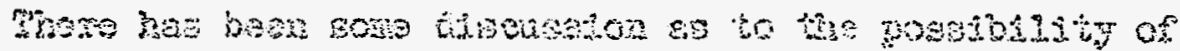

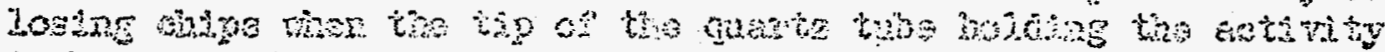

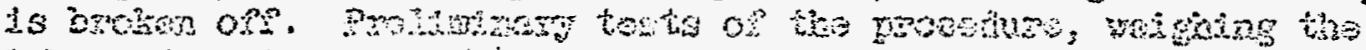

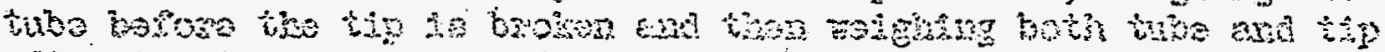

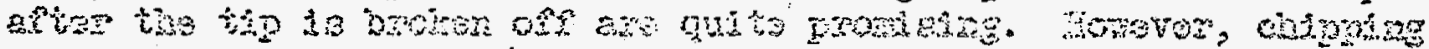

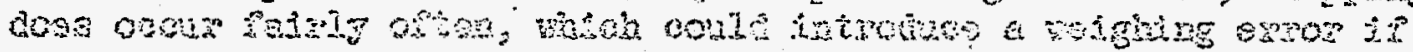
some chipe aro $10 \mathrm{st}$.

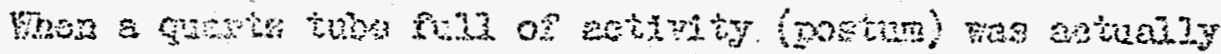
vesh, som why now

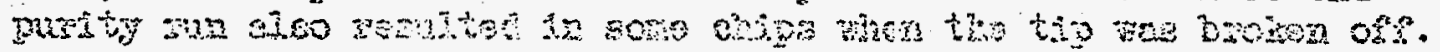

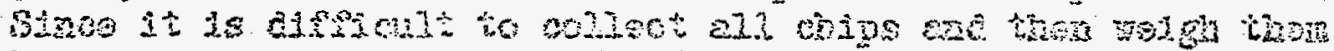

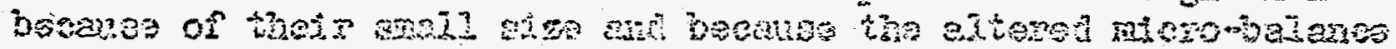

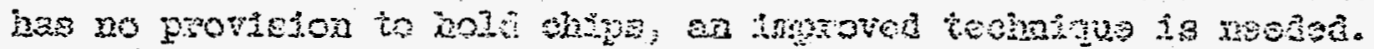

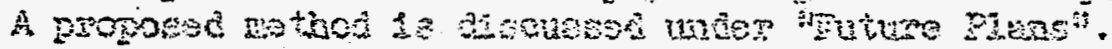

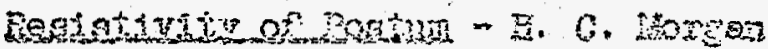

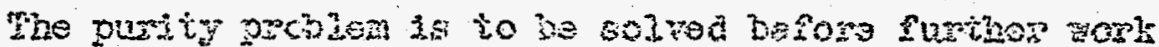
mill bo cone co tho resititivity of Dostum.

$$
\text { Earop Pressum ar Dostyn - I. S. Exooks }
$$

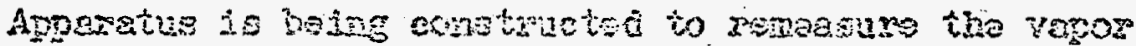

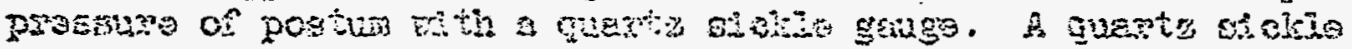

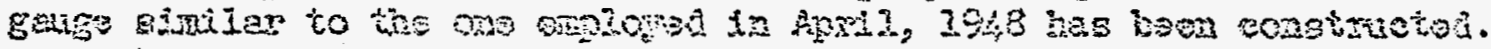

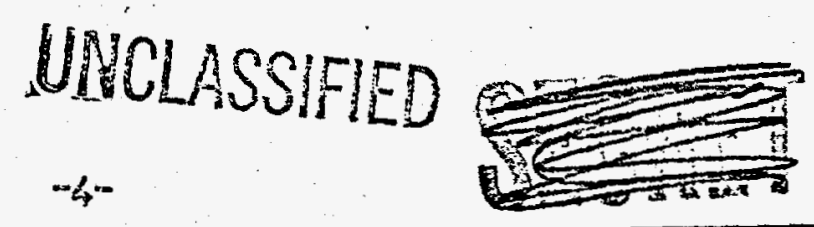




\section{$\because$ UNCLASSIFIED}

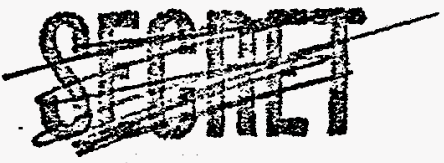

- $\quad$ 距 $\mathrm{L}$ 就 -133

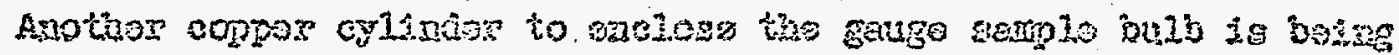

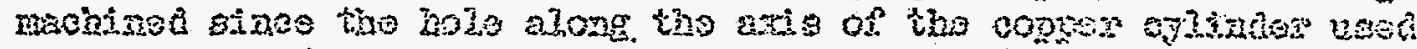

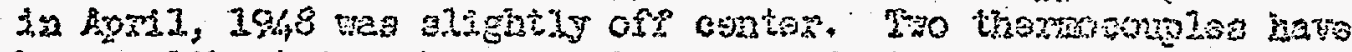

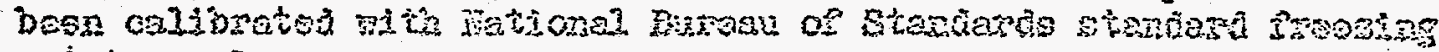
potat sanples.

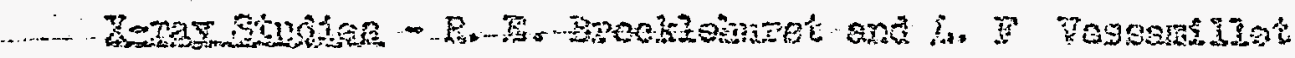

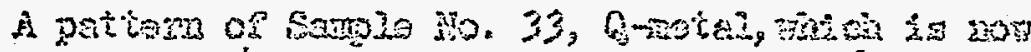

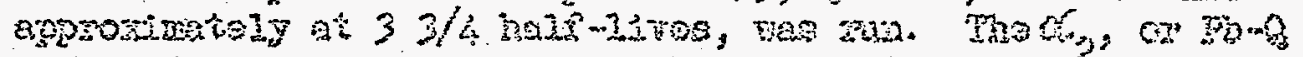

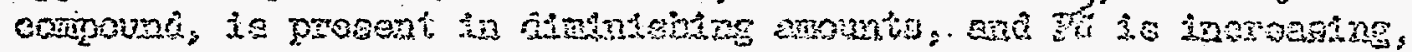
as orpotiot.

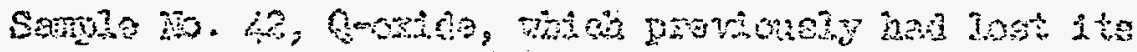

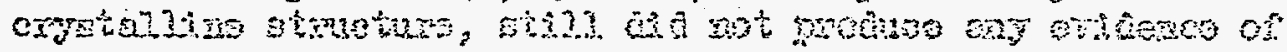
exyatatuaty.

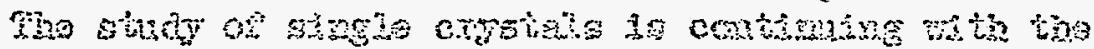

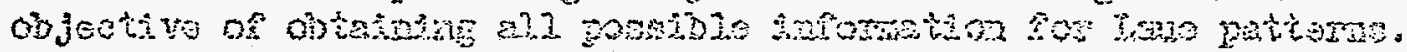

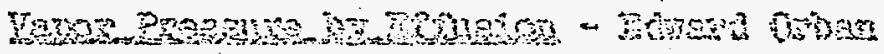

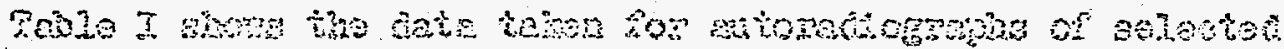

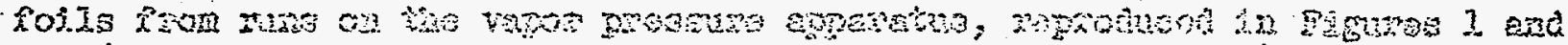

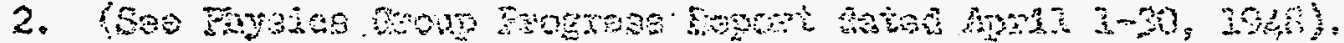

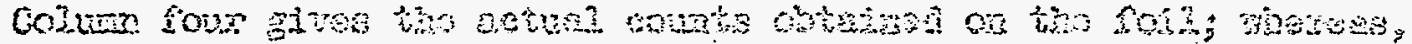

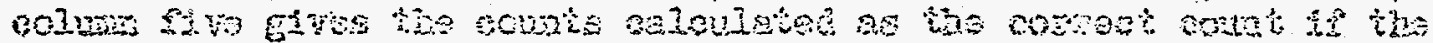

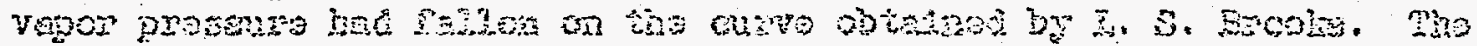

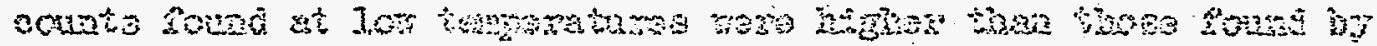

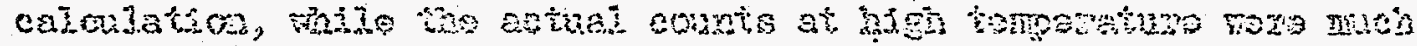

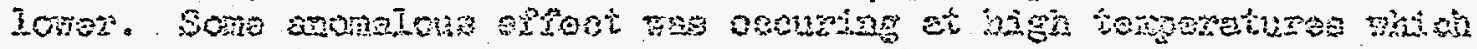

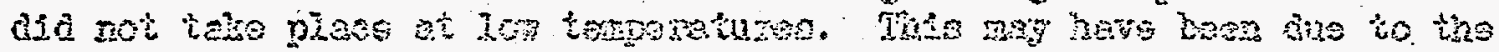

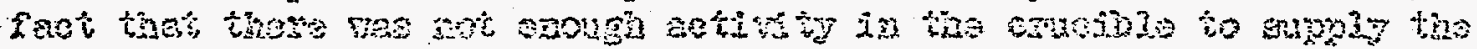

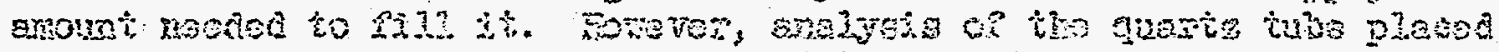

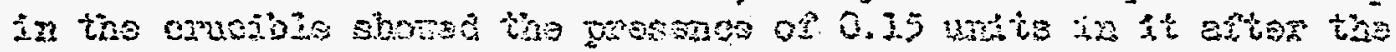

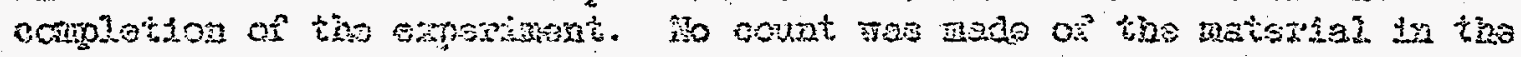
axiciola.

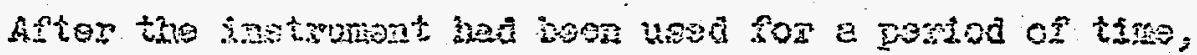

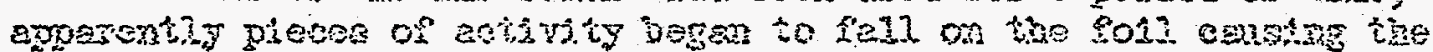

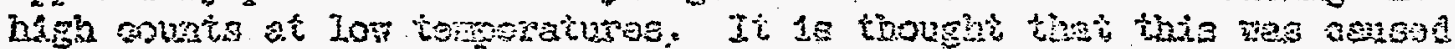

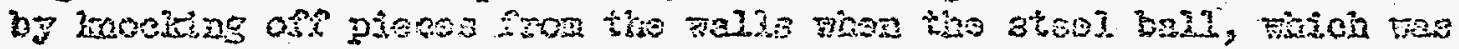

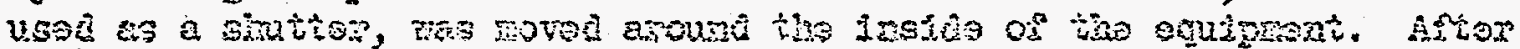

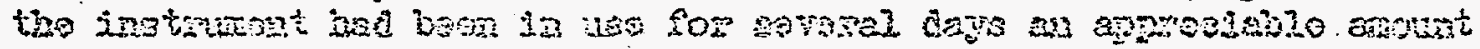

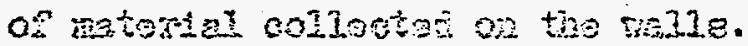

\section{UNCLASSIFED}

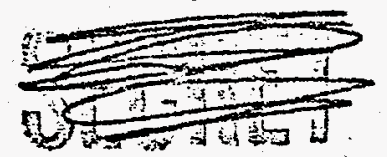




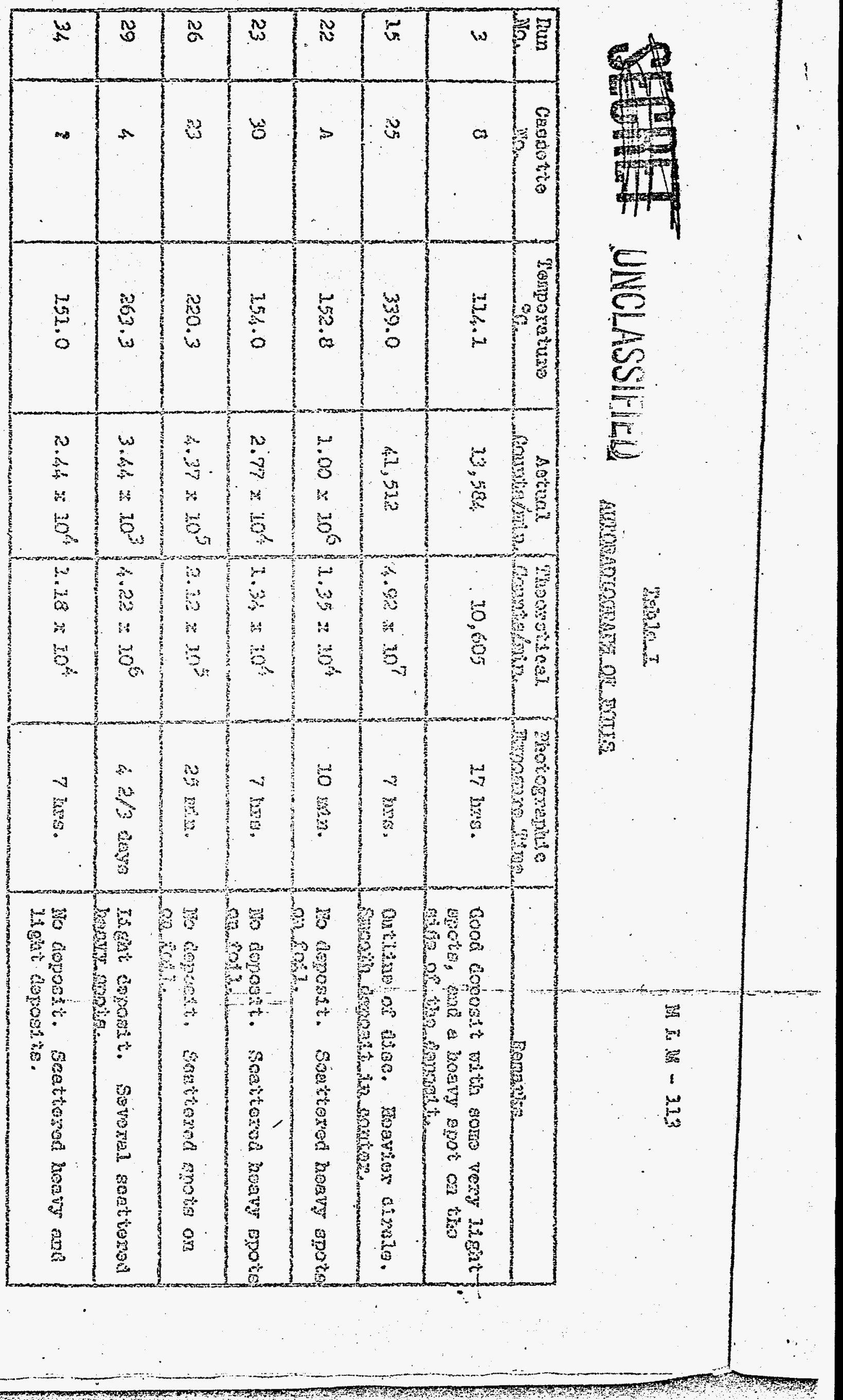



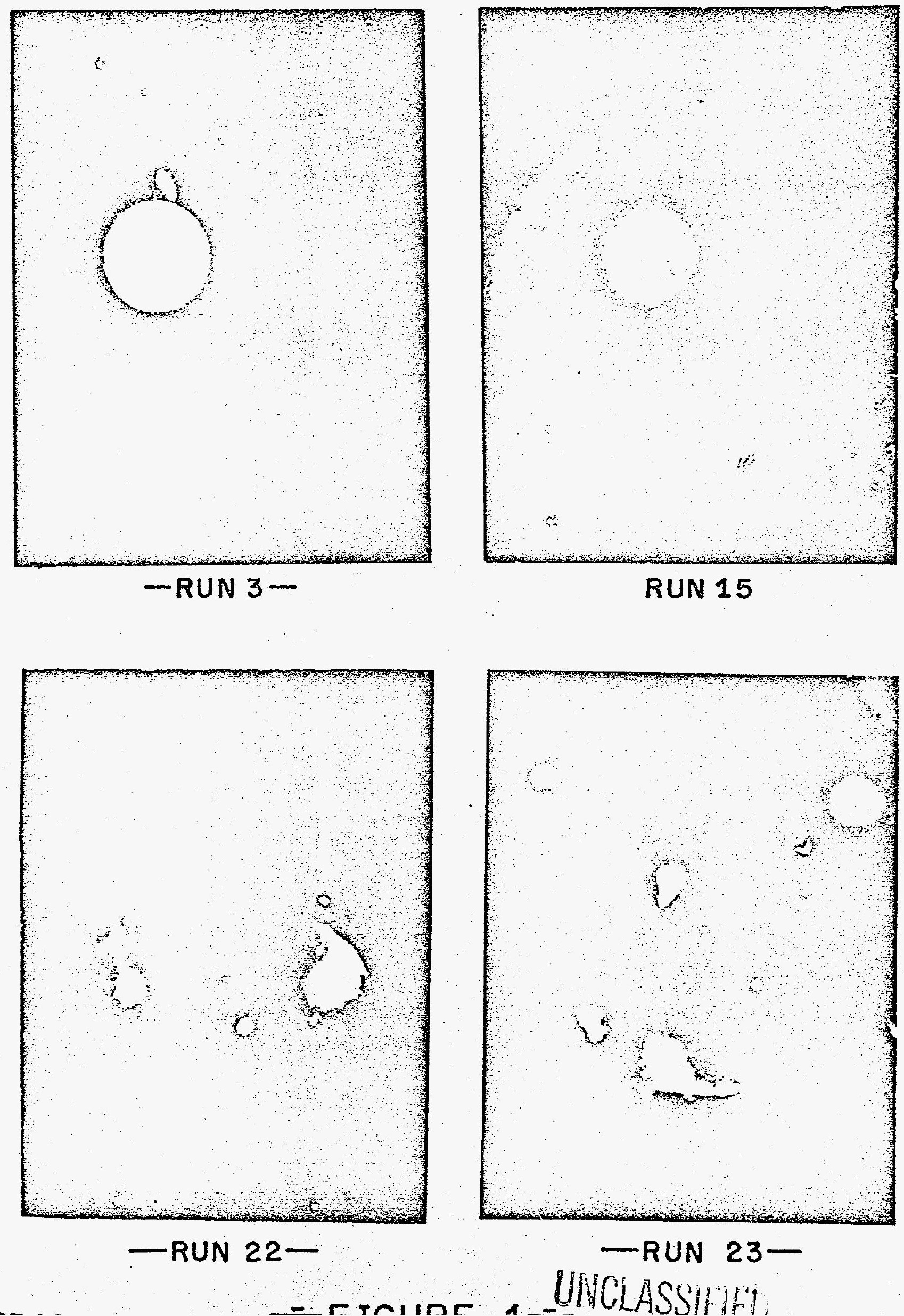


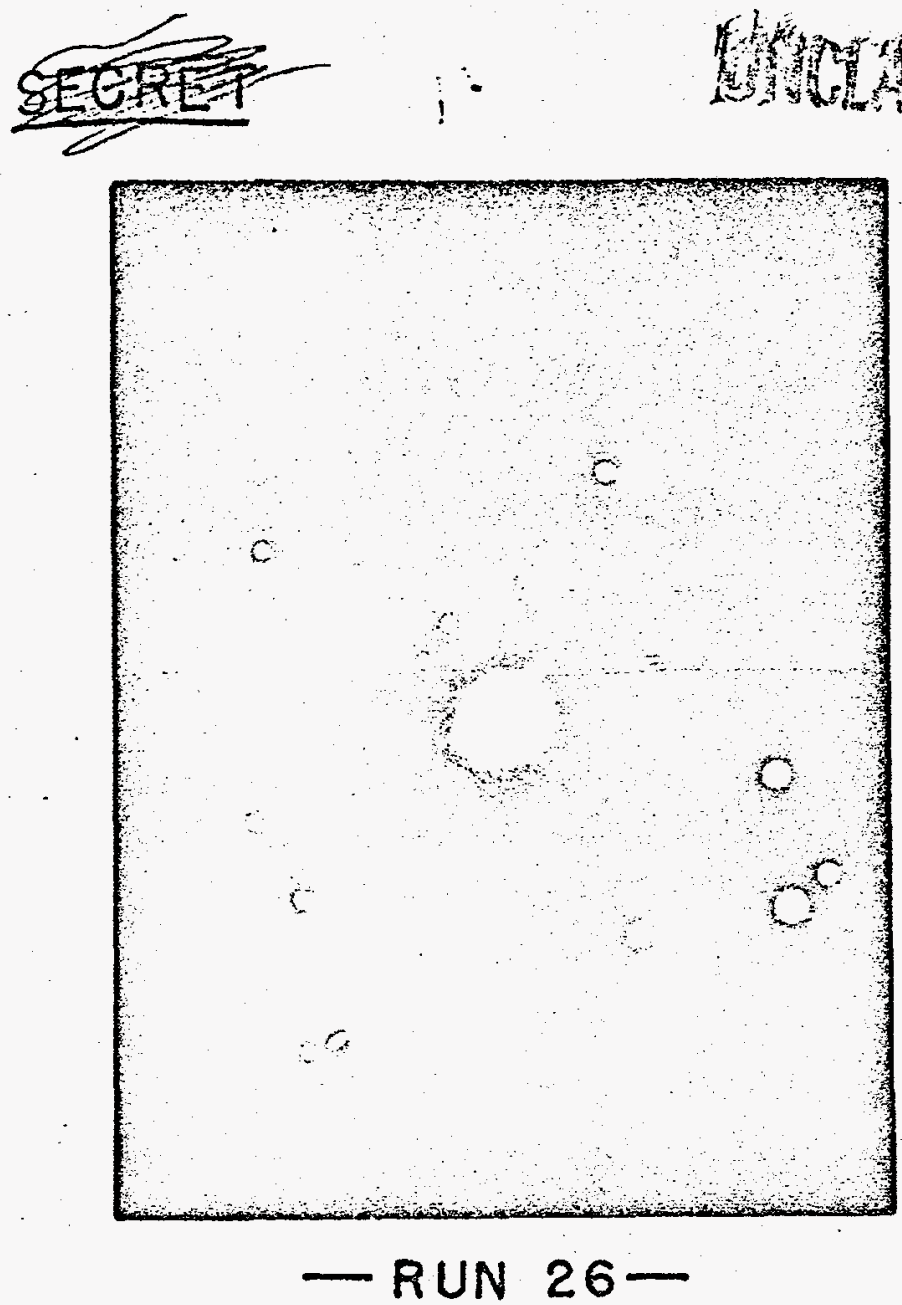

MIIM-113
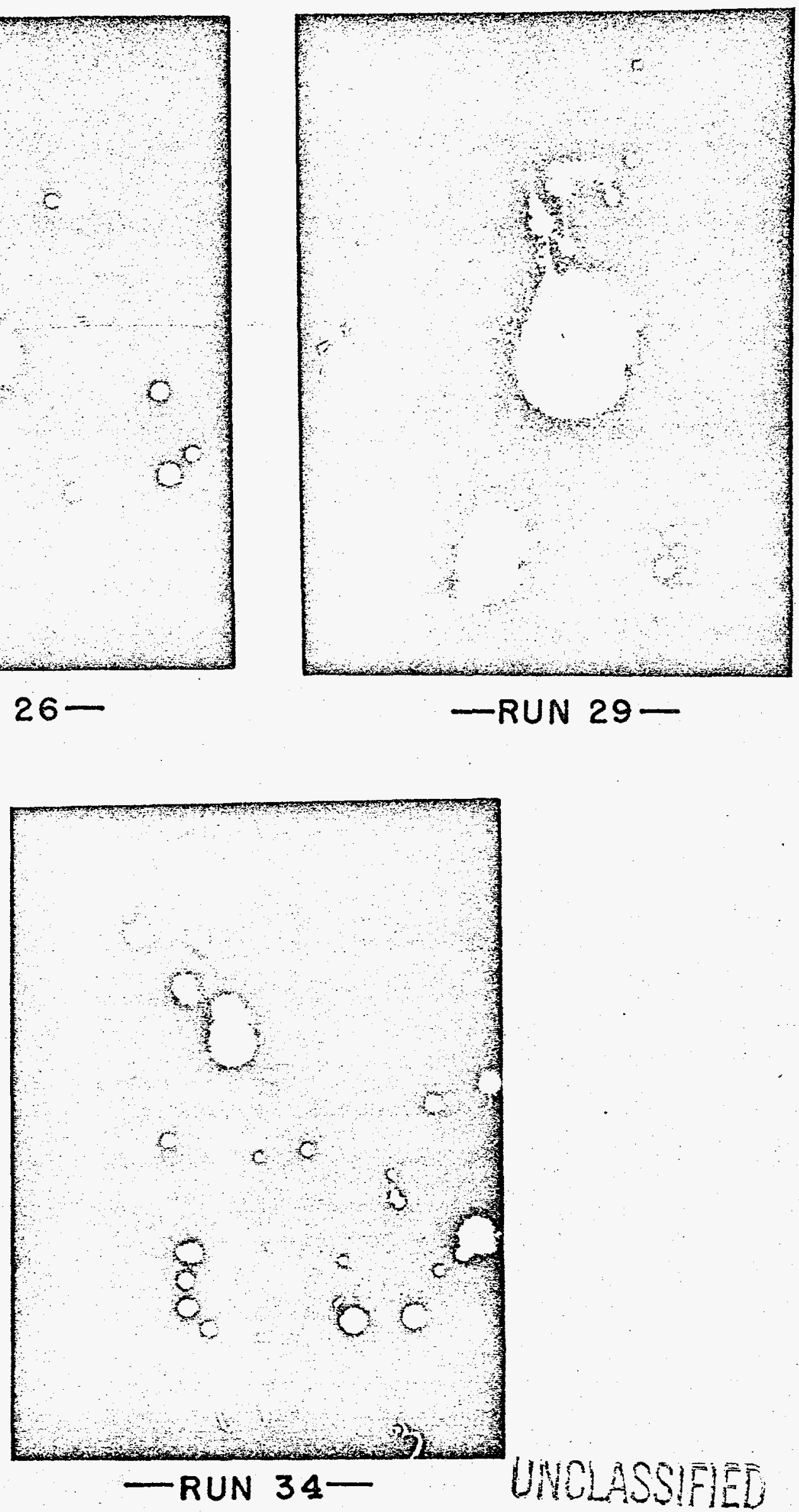


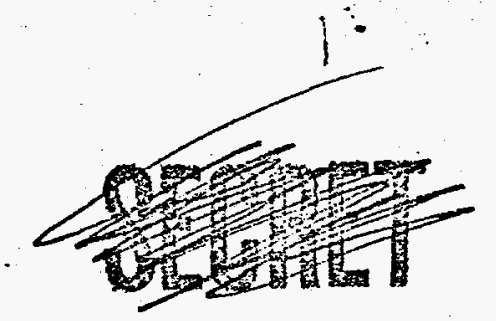

\section{UNCLASSFIED}

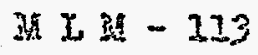

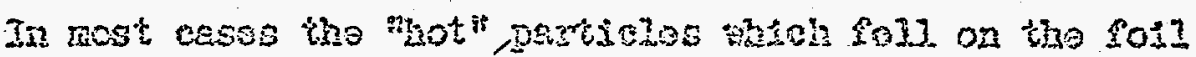

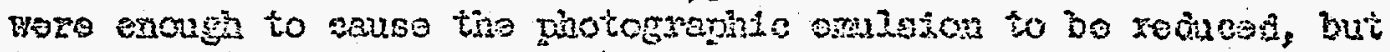
the copolt itselis res too 13 ght to bo onserval.

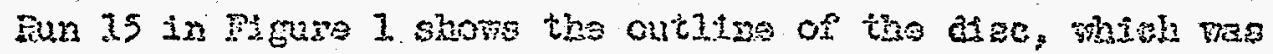

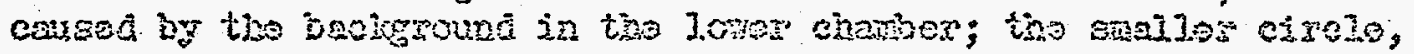

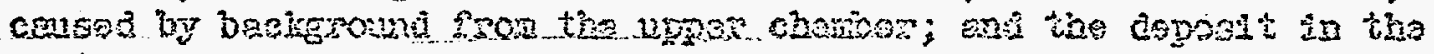
centor.

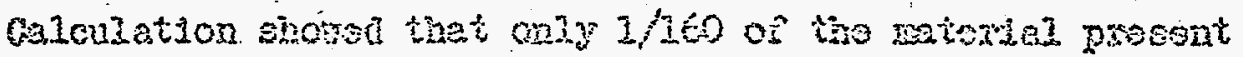

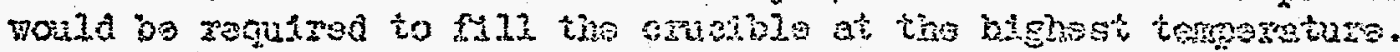

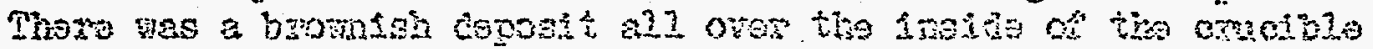

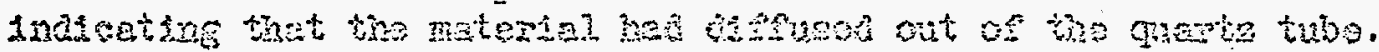

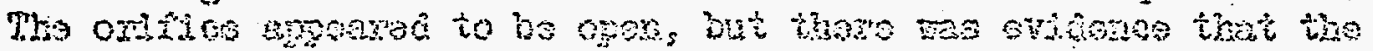

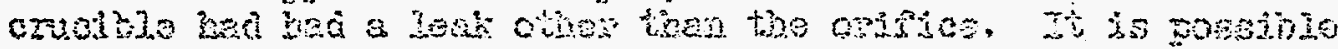

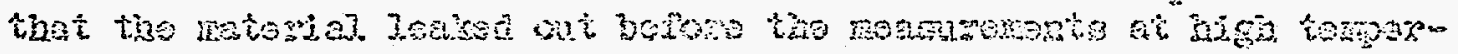

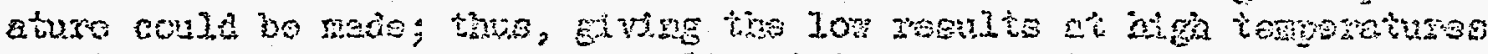

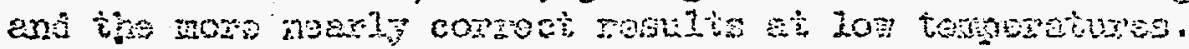

fenila.

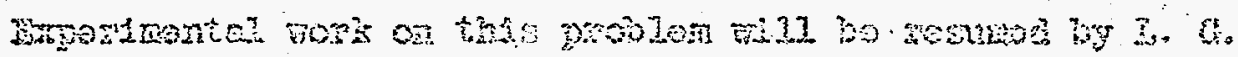

EMTHe Dins

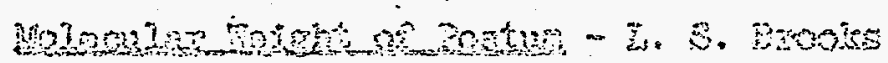

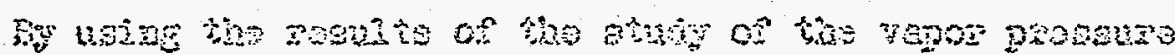

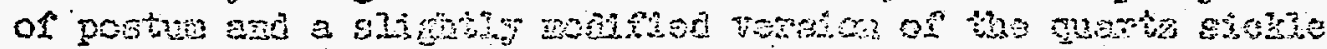

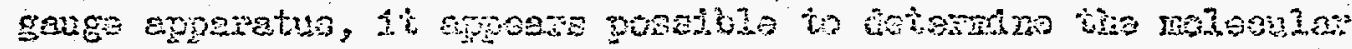
wigh of

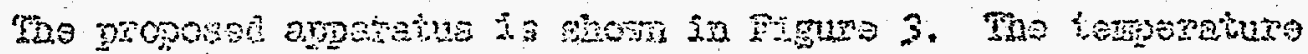
control appentus tha

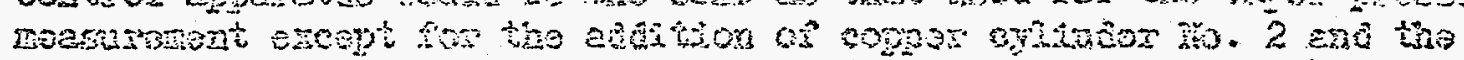

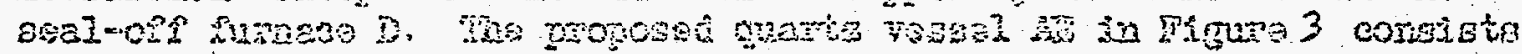

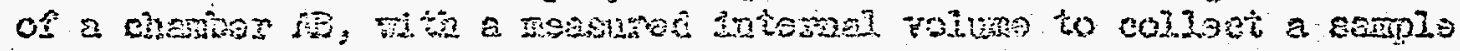

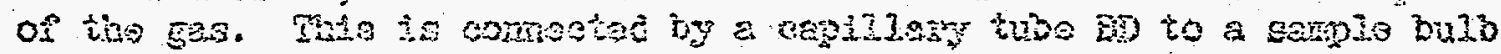

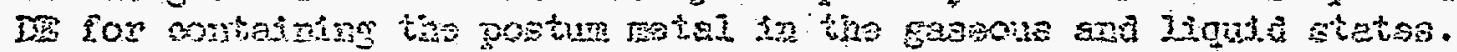

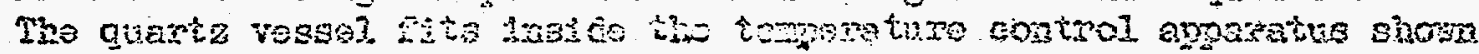

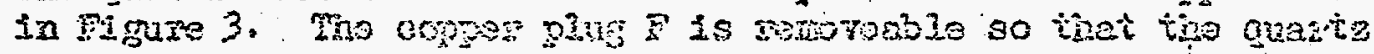

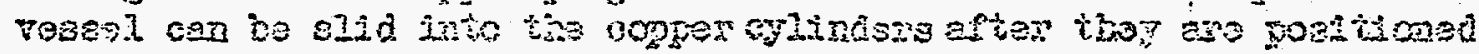
in tha surnaces.

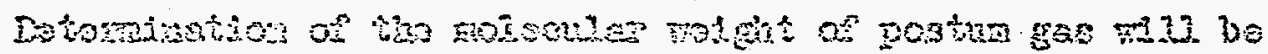

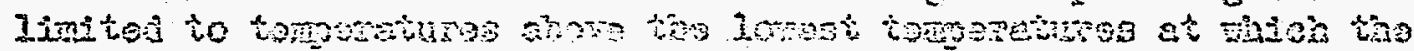

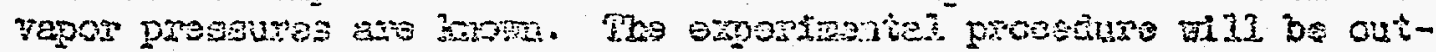

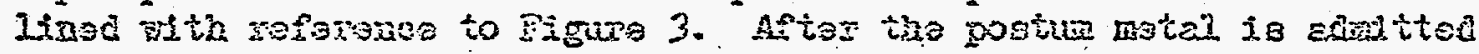

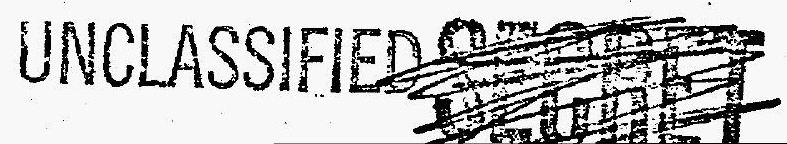




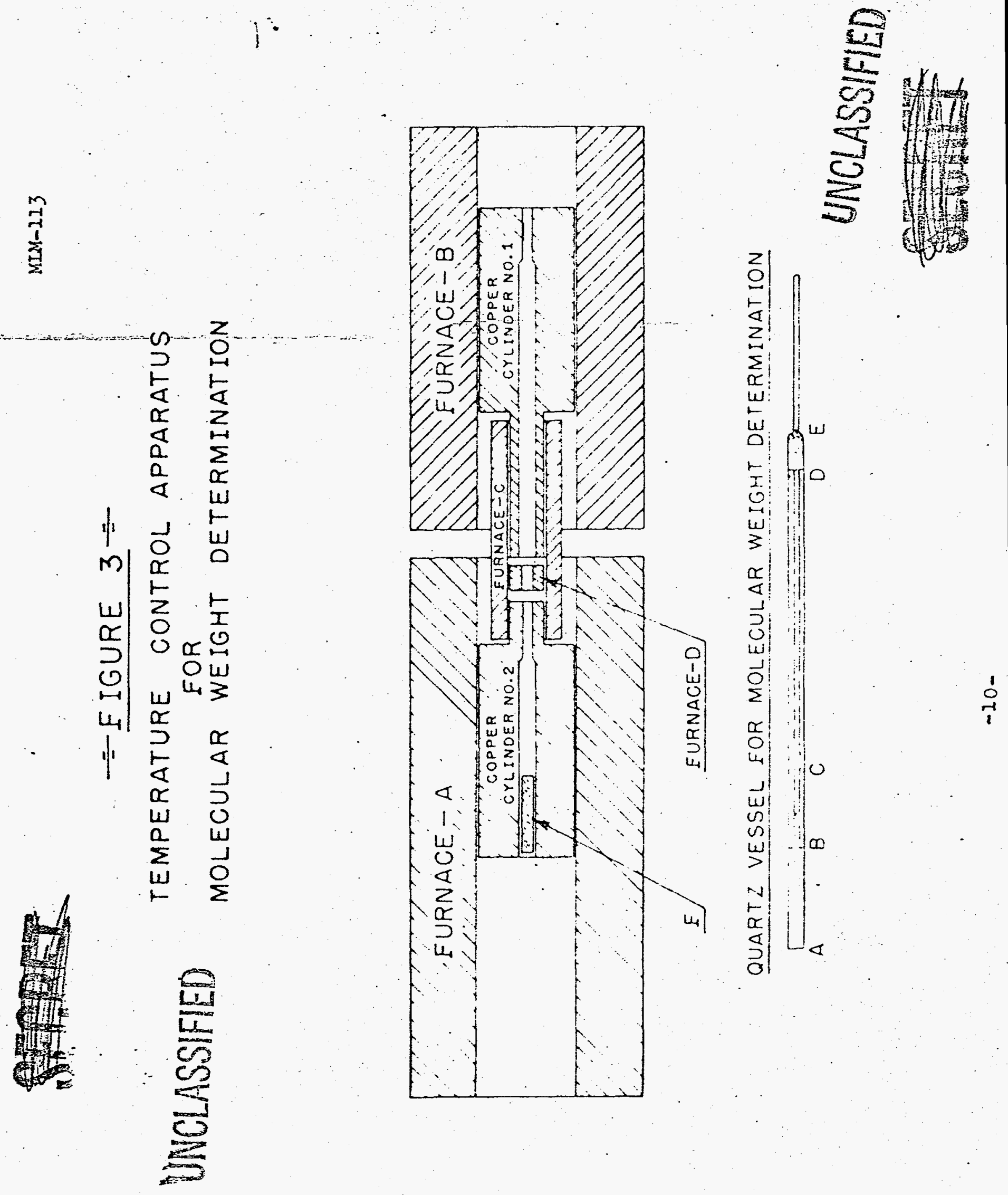




\title{
1. UNCLASIITE
}

\author{
$215-213$
}

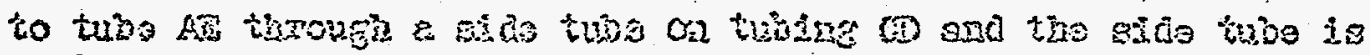

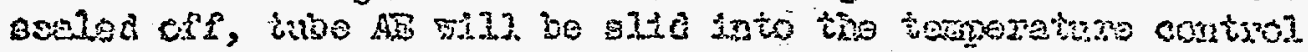

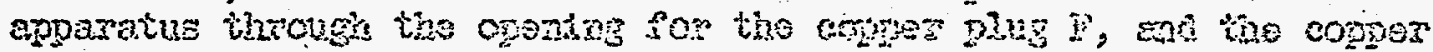

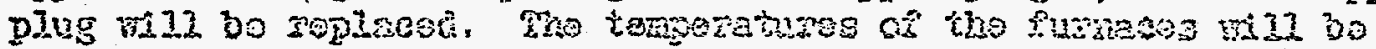

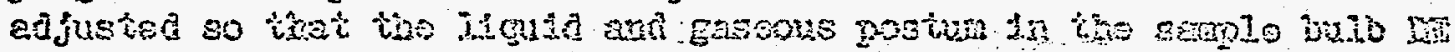

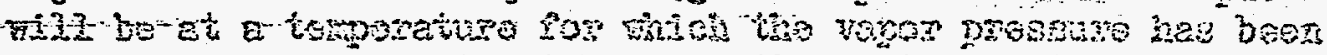

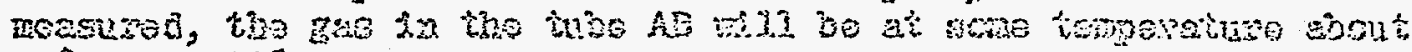

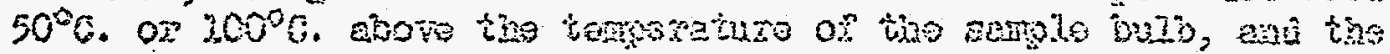

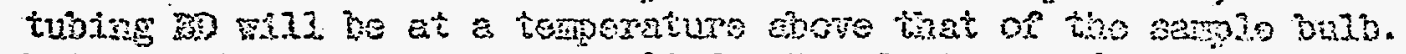

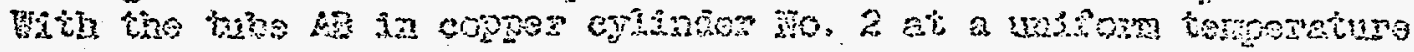

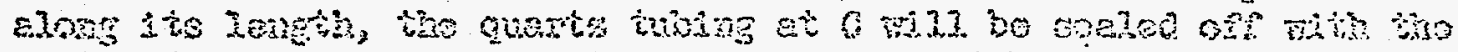

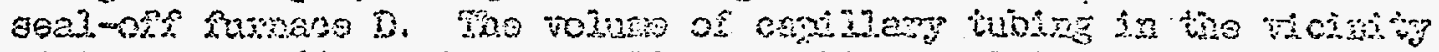

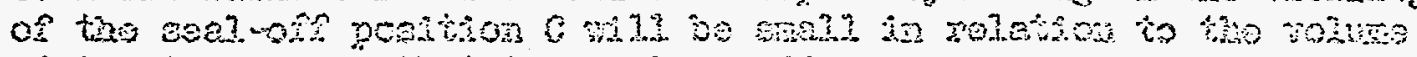

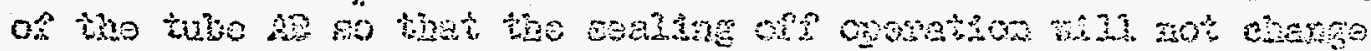

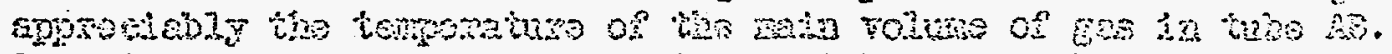

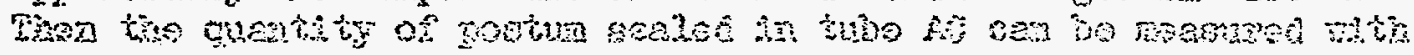

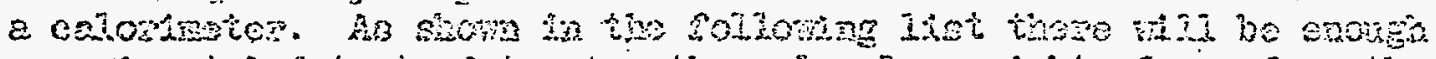

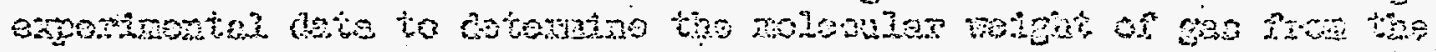
oguation of etste:

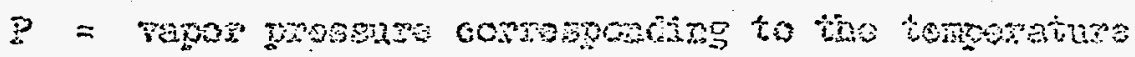

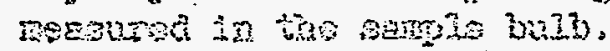

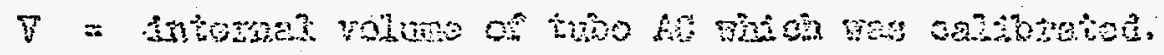

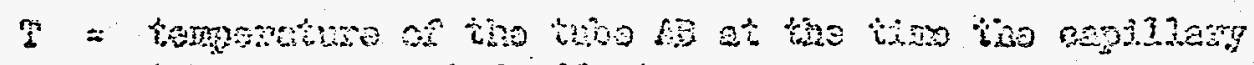

$$
\begin{aligned}
& \text { turing we asoled of at } 0 \text {. }
\end{aligned}
$$

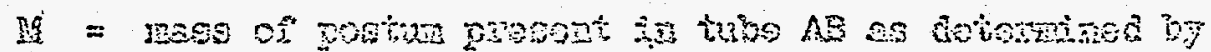

$$
\begin{aligned}
& \text { cine eslominetry. }
\end{aligned}
$$

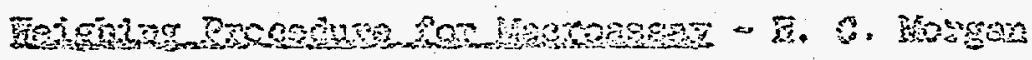

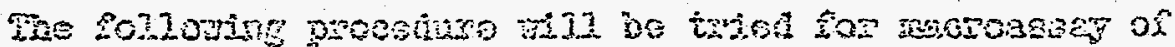

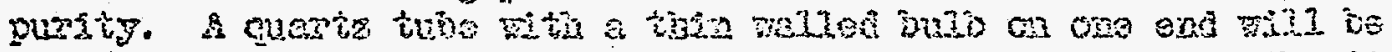

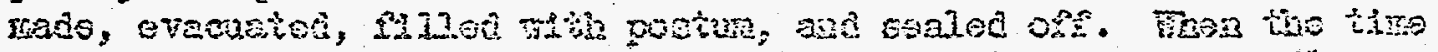

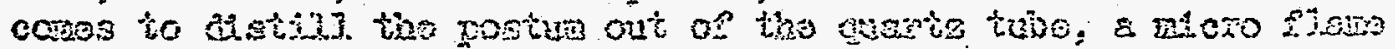

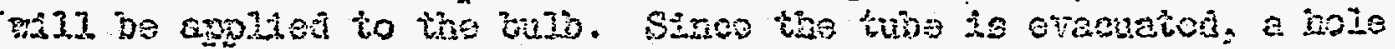

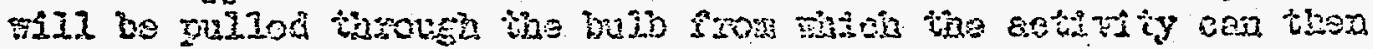

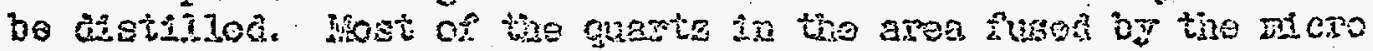
rlema

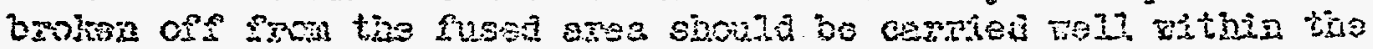
tubs by the turuen of nis.

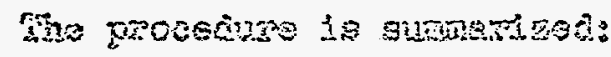

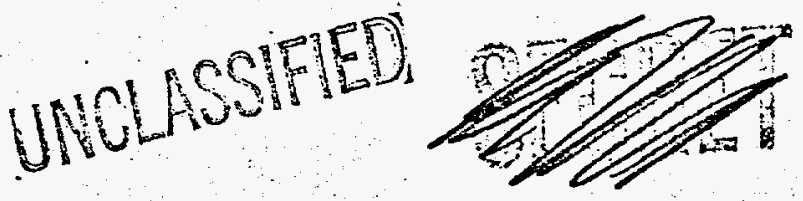


17057

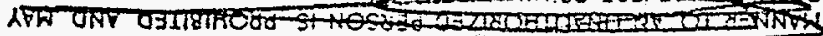

LM

0JONJWV SF C O O

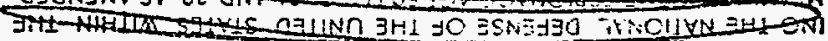

Dor $/ \mathrm{XER}^{2}$

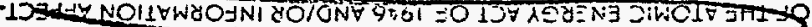

SNINVIW 3HINITIMA

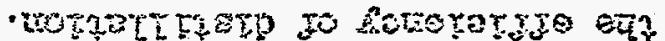

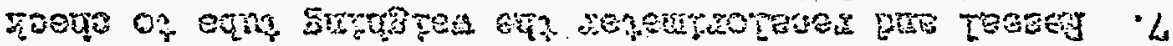

- sensora

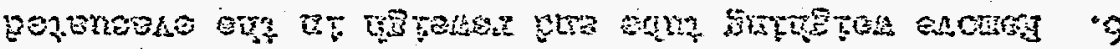

$\operatorname{con} ?$

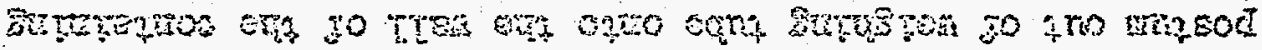

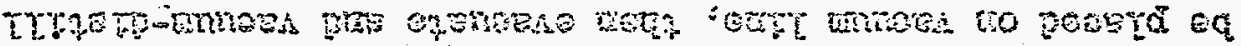
tee .

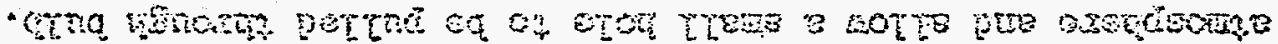

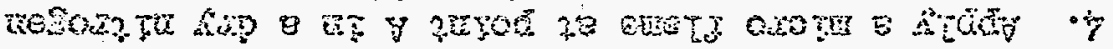

wo ur (4)

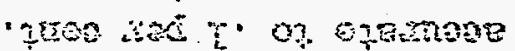

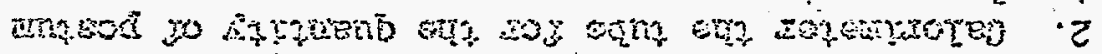

is axsas
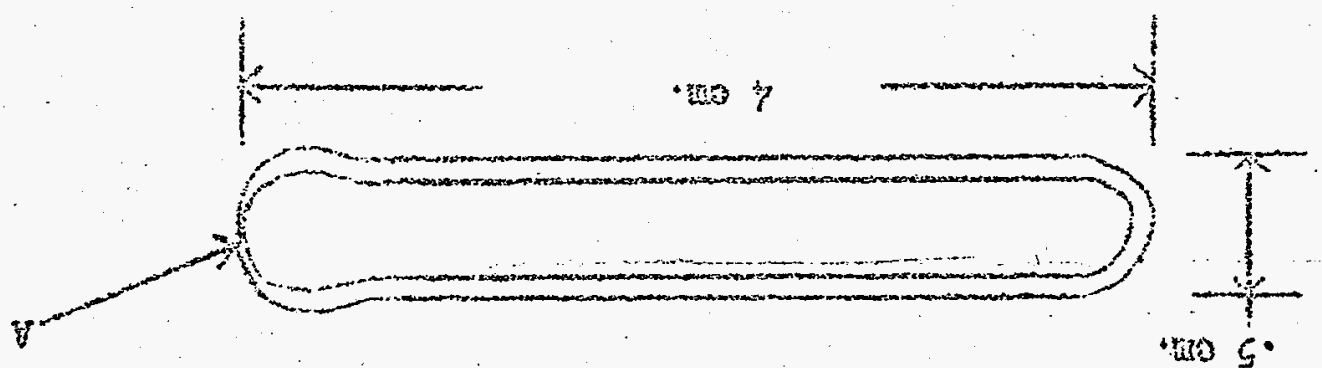

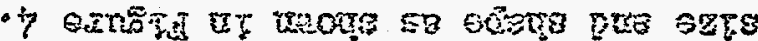

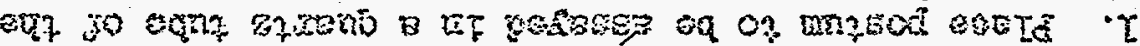

EIT - 琶等

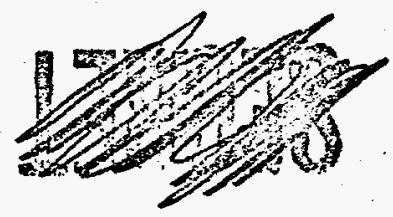

